\title{
Narratives of Dreams and Waking Thoughts: Emotional Processing in Relation to the COVID-19 Pandemic
}

\author{
Rachele Mariani*, Alessandro Gennaro, Silvia Monaco, Michela Di Trani and \\ Sergio Salvatore ${ }^{\dagger}$ \\ Department of Dynamic and Clinical Psychology, and Health Studies, University of Sapienza, Rome, Italy
}

OPEN ACCESS

Edited by:

Annunziata Romeo,

University of Turin, Italy

Reviewed by:

Agata Benfante,

University of Turin, Italy

Ksenija Bosnar

University of Zagreb, Croatia

*Correspondence:

Rachele Marian

Rachele.mariani@uniroma1.it

tORCID:

Sergio Salvatore

orcid.org/0000-0002-4583-8478

Specialty section:

This article was submitted to

Psychology for Clinical Settings,

a section of the journal

Frontiers in Psychology

Received: 21 July 2021

Accepted: 12 October 2021

Published: 02 November 2021

Citation:

Mariani R, Gennaro A, Monaco S, Di Trani M and Salvatore S (2021)

Narratives of Dreams and Waking

Thoughts: Emotional Processing

in Relation to the COVID-19

Pandemic.

Front. Psychol. 12:745081. doi: 10.3389/fpsyg.2021.745081
The Coronavirus-19 (COVID-19) pandemic posed a significant challenge to the physical, mental, and emotional well-being of each individual. It also brought the importance of daily emotional management for survival to the forefront of every human being. Our study aims to explore whether emotional processes perform different functions during waking thoughts and night dreams during the first lockdown in Italy. Utilizing Multiple Code Theory (MCT), our goal is to verify whether waking thoughts facilitate a functional disconnection in order to manage the trauma caused by COVID-19. Two online forms were distributed to random participants in the general population, presenting a total of 49 reports of night dreams (23 males; mean age 33.45 ds. 10.12; word mean 238.54 ds. 146.8) and 48 reports of waking thoughts (25 males; mean age 34.54 ds. 12.8; word mean M. 91 words ds. 23). The Referential Process linguistic measures and Affect Salience Index were utilized. It was found that Affect Salience is present in both dreams and in waking thoughts; however, Referential Activity was higher in dreams and Reflection and Affect words were higher in waking thoughts. Two different processes of emotional elaboration emerged. The results highlight the use of greater symbolization processes during dreams and a higher emotional distance in waking thoughts. These results confirm that during the nocturnal processes, there is greater contact with the processing of trauma, while during the diurnal processes, defensive strategies were activated to cope with and manage life via a moment of the defensive disruption of daily activities.

Keywords: dreams, linguistic features, referential process, COVID-19, affective salience

\section{INTRODUCTION}

\section{A Traumatic Global Experience: Dreaming and the Narrative Process During COVID-19}

The present research project aims to offer an analysis and understanding of affective processing processes during a very difficult moment of human existence, such as the experience of the COVID19 pandemic, which involved every single inhabitant of the earth.

The processing of emotional trauma is a theme that has been extensively studied (Murray and Segal, 1994; Rachman, 2001), but to date, new questions have emerged regarding it. Recently, the spread of the COronaVIrus Disease 2019 (COVID-19) created a unique historical context 
(Viscuso and Mangiapane, 2020), which we can consider as a real collective event that we assume to be universal. The entire world population felt at risk of extinction (Diamandis, 2021) and each human being has had to emotionally and cognitively adapt to it (Daly and Robinson, 2021). The lockdown rules imposed the safest procedures possible at the time, such as the mandate to wear masks and the "stay at home" imposition. After 1 year, these protocols are the "new normal" (Rab et al., 2020), but this new reality has had a huge impact on social life (Beam and Kim, 2020), work conditions (Bonacini et al., 2021) and the emotions related to these changes (Li et al., 2020). Research immediately showed that the relationship between the COVID19 pandemic and mental disorders (Castellini et al., 2021; Czeisler et al., 2021; Wang et al., 2021) increased, when compared to pre-pandemic times (Rossi et al., 2020). While many researchers have focused on the impact of COVID-19 on mental health, the intent of this work is to explore, given the same traumatic event, how emotional processing processes perform different functions during dreams and waking thoughts. We utilized the exploratory medium of writing to understand the different emotional processes that occur during the day and during the night. Historically, narratives are the most direct modality used to explore the cognitive and emotive reorganization of individuals (Polkinghorne, 1995). The theoretical models that analyze the narratives (Pennebaker, 2000; Solano, 2013; Bucci, 2021a) highlight how it is possible to understand the emotional organization and the structure of the person's defenses during a particular moment in life. The autobiographical narrative capacity is closely linked to the use of defenses and the ability to stay in contact with the different emotions that the events of external and internal reality create in each of us (Boag, 2020). For example, studies on the process of psychotherapy have shown how the progressive lowering of the ego's defenses allowed for a greater awareness of one's own experiences (Kramer et al., 2020; De Roten et al., 2021). Most researchers used the analysis of narratives to capture the experience and the cognitive and emotional elaboration put in place to face and cope with the pandemic (De Leo and Trabucchi, 2020; Negri et al., 2020; Creese et al., 2021; Herbert et al., 2021). At the same time, many studies have focused on dreams, as carriers of a common experience and the unconscious elaborations which emerged (Iorio et al., 2020; MacKay and DeCicco, 2020; Mota et al., 2020; Pesonen et al., 2020). In our work, we have tried to combine and compare the two types of writing to investigate how mental processes are adaptive to highly stressful events trying to preserve the main tasks of daily life.

\section{Emotional Communication Processing and Affective Salience: Two Prospectives in Exploring the Language of Emotion}

One theory of emotional processing that has explored the processes of integration and disconnection of traumatic experience is the Multiple Code Theory (MCT). This model poses that information is processed in parallel (McClelland et al., 1989) among three different systems, which organizes the experience in a global and raw way: (1) the subsymbolic coding system is characterized by experience gradients, and they manifest as sensations and feelings in all sensory modalities, as well as in physical and motoric experience; (2) the non-verbal symbolic coding system, which is delegated to representations, images, and metaphors; (3) and the symbolic verbal coding system, which concerns words. From the beginning of life, humans think and interact in subsymbolic and symbolic formats (Bucci, 2021b). Bucci (2021b) argues that a Referential Process (RP) connects these three types of processing systems by transforming information from one to another. The RP allows people to express their emotional experiences into words. The theory has also been updated to include new advancements in social neuroscience, such as research on mirror neuron networks, social cognition, and embodied communication (Goleman, 1998; Gallese, 2009; Borghi and Cimatti, 2010). The RP and emotional communication are connected to Damasio's notion of dispositional representations (Damasio, 2010) that provide a neurobiological basis for the concept of emotional schema. These innate dispositional representations can be associated to the arousal/emotional activation and to a non-conscious state of the self where raw bodily aspects are totalizing. Different theoretical perspectives suggest that affect and emotions could be conceived of in terms of the basic processes laying at the core of the self (see the notions of core-self by Panksepp, 1998, 2005) and the proto-self by Damasio $(1999,2010)$. These basic processes represent the first, fast, and frugal modes through which the subject appraises the environmental patterns (Gigerenzer and Goldstein, 1996) to trigger and orient cognitive processing (Muramatsu and Hanoch, 2005). For example, Barrett et al. (2007) and Barrett (2017) theory of constructed emotions suggests that affect guides actions and constructs perceptions in the present. Emotions are not distinct entities; rather they result in a continuous process aimed to map out the demands of the environment and the set modes to address its variations (Gross and Barrett, 2011). It has been highlighted (Posner et al., 2005) that distinct neural pathways do not serve distinct emotions, but that two underlying neurophysiological dimensions are used to organize emotions: that of arousal (the extent to which an emotion is associated with an individual sensation of energy) and valence (the extent to which an emotion reflects a negative or positive state of mind; Barrett et al., 2007). In sum, in emotion processing, arousal and valence are classification dimensions which organize the basic process aimed to monitor each individuals' global relationship to the world that we refer to as emotion (Barrett and Lindquist, 2008).

Emotional arousal could be acknowledged as the extent of activation experienced as a reaction to stimuli (Lang et al., 1999; Deckert et al., 2020). However, arousal represents an autonomous psychological concept associated with emotional states that is indexed by the activation of the sympathetic nervous system, the autonomic nervous system, or the endocrine system (Russell and Barrett, 1999; McGaugh, 2004). Accordingly, in their review, Storbeck and Clore (2008) highlight the role of the production of arousal to intensify perceptions, evaluations, and enhanced long-term memory for events. This concludes that while the valanced affective cues serve as information about value, the arousal dimension provides information about the urgency to intensify processing strategies. 
In sum, in analogy to several psychoanalytic streams of thought (Klein, 1937; Bion, 1967; Green, 1977; Matte Blanco, 1981; Bornstein and Masling, 1998; Beebe and Lachmann, 2002), arousal and valence could be understood of in terms of the basic affective representations regulating and organizing mental functioning which, in turn, is organized into emotions in order to map out answers to environmental demands.

\section{Connecting/Disconnecting Emotional Experience to Language}

Scherer (2005) posits that the episodes which constitute an emotional schema's combinations, called "profiles of appraisal," are made up of the activation of the schema's affective core in various circumstances. The speakers or writers (in our researchwriters) are often not directly aware of the components of the affective core that organize the emotional schema, and it is not often clear how they feel at the moment. Naming emotional labels or trying to explain feelings is often opposing to the processes at play when trying to understand emotional feeling, according to MCT (Bucci, 2021a). The RP involves expressing the parallel flow of multiple experiences in the discrete single channel of the verbal mode. This process is based on three specific major functions of connecting experience to words: Arousal, Symbolizing, and Reflection/Reorganizing. Arousal is concerned with the activation of content that is outside or within the boundaries of awareness. The Symbolizing function follows the arousing material that has been accumulating outside of awareness and takes it in to a more accessible form, linked to linguistic form. A specific experience occurs that symbolizes components of a certain emotional schema that the individual can vocally convey in the form of a story, a memory, or a dream. Then, after the schema has been experienced and portrayed as a narrative or played out in the relationship, fresh reflections on previous experiences might combine during Reflection/Reorganization. All people who tell or write about their own experiences have the power to activate the RP by going through all three processes.

Bucci and Maskit (2007) hypothesize that if the RP is disrupted (e.g., by conflict or trauma), or fails to develop adequately, the verbal and non-verbal systems within the schemas may be disconnected, thereby affecting the organization of the schemas, the regulation of emotional arousal, and the construction of emotional meanings. The idea of disconnection within the emotional schemas can be applied to both somatic and mental pathology (Di Trani et al., 2018; Negri et al., 2019; Mariani et al., 2020; Negri and Ongis, 2021). A specific pattern of disconnection is given by the high use of defenses, such as rationalizations or an abstract language (Renzi et al., 2020; Mariani and Hoffman, 2021; Negri and Ongis, 2021). Other research highlights how high levels of arousal and rationalization can activate a disconnection, which generates a disorganization phase (Bucci and Crisafulli, 2021).

\section{Aim of the Study}

Given this collective traumatic event, our research aims to explore whether emotional processing mechanisms perform distinctive tasks when writing reports of waking thoughts vs. writing reports of night dreams during the first lockdown in Italy. Our goal was to explore whether the reports of waking thoughts showed a functional disconnection to handle the traumatic event caused by the COVID-19 pandemic, as per MCT (Bucci, 2021b). The dream writing process activates an integration of the RP in order to integrate and elaborate the traumatic experience of the pandemic during sleep. During the day, emotional elaboration is functionally deactivated to manage normal adaptive functions. More specifically, we hypothesized that:

(a) Reports of waking thoughts and night dreams will show the same levels of arousal;

(b) Reports of night dreams will present an integrated RP, showing higher Referential Activity, which is useful in elaborating the COVID-19 pandemic experience;

(c) Reports of waking thoughts will show higher cognitive and abstract functions to explain emotional activation;

(d) The arousal activation will present different relations to the symbolizing process in reports of waking thoughts and night dreams.

\section{MATERIALS AND METHODS}

\section{Participants}

The sample was recruited from the general Italian population during the first week of the first lockdown. Each person was randomly assigned to one of two groups. Participants completed the informed consent and a sociodemographic questionnaire. One group was asked: "What did you dream about tonight? Write down your dreams freely during the lockdown." A group of 49 individuals (23 males and 27 females) participated in this task. The mean age of participants in this group was $33.45(S D=10.12)$. Of these participants, 30\% graduated college and $70 \%$ had one degree; $14 \%$ lived alone, $62 \%$ lived with family, and $24 \%$ with lived with a cohabitant; $40 \%$ described themselves as single and $60 \%$ reported to be in a relationship. The other group was asked: "How are you experiencing this period of lockdown? Freely write about your experience.” A group of 48 individuals (25 males, 23 females) participated in this task. Group members had a mean age of $34.54(S D=12.8)$. Of these participants, $27 \%$ graduated and $73 \%$ had degree; $19 \%$ lived alone, 52\% lived with family and 29\% lived with a cohabitant; $35 \%$ described themselves as single and $65 \%$ reported to be in a relationship. The dreams dataset had a mean word count of $238.54(S D=146.8)$ and the waking thoughts report word count was smaller $(M=9, S D=23)$.

This study was carried out in accordance with the code of ethics of the World Medical Association (Declaration of Helsinki), and approved by the Ethics Committee of Department of Dynamic, Clinical and Health Psychology of the University "Sapienza."

\section{Measures}

\section{Affective Salience Index}

This computerized measure assesses for Arousal in written text. The affective salience index (ASI) is based on the view that affect is a global embodied source of meaning (Fornari, 1976; 
Salvatore and Freda, 2011; Valsiner, 2021)—namely, that patterns of activation of the whole body provide the subject with the experience of the world as a global entity. A preliminary version of ASI was used in a recent study to analyze the evolution of the meaning behind the characterization of dreams of a patient throughout the course of psychotherapy (Gennaro et al., 2020). In the context of that study, ASI proved successful in estimating the saturation of the affect-laden meanings in the patient's dreams. In this study, ASI followed a meaningful, though non-linear trajectory, which was globally indicative of their progressive increase of the patient's capacity to elaborate unconscious, affectively relevant areas of the mental landscape. Further studies conducted (Gennaro et al., 2020) which compared ASI to an individual's physiological index of propensity to affective arousal (measured by Heart Rate Variability), transcript semantic complexity (measured as Semantic Entropy Index) and lexical syntactic complexity (measured through Flesch Vacca Index), proved ASI to be a reliable text-based index able to detect the affect intensity contribution of affective meanings to the whole semantic content of the text under investigation. Accordingly, we consider ASI as a proxy of affective intensity, not so much as the sum of single emotions, but as the structuring of coactivation of affect, paving the way for the expression of emotions (Berrios, 2019).

ASI is based on an automated procedure of textual implementations by the ACASM procedure (Salvatore et al., 2012, 2017) via T-Lab software. First, a Lexical Correspondence Analysis (LCA), based on the textual context*lexical unit matrix allows to define a factorial space, where each of the factors maps a component of the meaning being activated within the whole textual corpus. Moreover, the LCA output provides the coordinate on the factorial space of each textual unit in which the textual corpus is segmented. The factorial coordinate of the i-th textual unit on the $\mathrm{j}$-th factorial dimension is a measure of the degree of their association-the higher the coordinate, the higher the association is, therefore, the higher the contribution of the $\mathrm{j}$-th factorial dimension is to the meaning of the $\mathrm{i}$-th textual unit.

Factorial coordinates are used to compute the ASI. More specifically, the ASI is calculated for each textual unit, as its Euclidian distance from the origin of factorial space. It is worth highlighting that the Euclidian distance is computed by using the coordinates of the first two factorial dimensions only, as in equation (1). This is so because the ASI assumes that the first two dimensions are the computational equivalents of primary affective dimensions.

$$
\mathrm{ASI}_{\mathrm{t}}=\sqrt{\mathrm{C}_{\mathrm{F} 1(\mathrm{t})}^{2}+\mathrm{C}_{\mathrm{F} 2(\mathrm{t})^{2}}}
$$

$\mathrm{ASI}_{\mathrm{t}}$ stands for the Affective Saturation Index of the textual unit $t . \mathrm{CF}_{(\mathrm{t})}$ and $\mathrm{CF}_{(\mathrm{t})}$ stand for the factorial coordinates of the textual unit $t$, on the first and second factorial dimensions, respectively. From (1), it can be seen that ASI increases when one or both of the factorial coordinates increase. Accordingly, ASI can be interpreted as a measure of the magnitude of the contribution of the two first dimensions of the factorial space to the meaning of the textual unit-the higher the ASI, the greater the contribution. Therefore, ASI can be considered an index of the degree of saturation of the affective meanings comprising the textual unit.

\section{Italian Weighted Referential Activity Dictionary}

The Italian weighted referential activity dictionary (IWRAD) is a computerized measure (Mariani et al., 2013) in the Italian language which is able to detect the Symbolizing Phase. It contains a list of 9,596 frequently used Italian words, each assigned a weight between 0 and 1 , with 0.5 as the neutral value. A high score represents a high level of RA, which corresponds to a high level of concreteness, specificity, clarity, and imagery in the speech sample. Part of the value of the IWRAD derives from its power to assess a particular linguistic style (rather than only focusing on content) and to represent the unintended aspects of emotional involvement (Maskit, 2021). Linguistic measures of the Referential Process can be processed by the Discourse Attribute Analysis Program (DAAP; Maskit, 2021). In this study, the Italian version, IDAAP (Italian Discourse Attribute Analysis Program) was utilized.

\section{Italian Weighted Reflection and Reorganization List}

The Italian weighted reflection and reorganization list (IWRRL) is a computerized measure of the Reflection/Reorganization process in the Italian language. It contains a list of 1,633 frequently used Italian words, each assigned a weight between 0 and 1, with 0.5 as the neutral value (Negri et al., 2018). A high score on this measure represents high competence in reorganization and reflection in speech, referring to the degree to which the speaker is trying to recognize and understand the emotional significance of an event or set of events in their own or someone else's life, or in a dream or fantasy. It is not about abstract reflection, but rather a person's reasoning related to an experience that has been vividly experienced. Through IWRRL, it is possible to detect and model the reorganizing phase of the referential process. RR measures can be processed by DAAP (Maskit, 2021).

\section{Italian Reflection Dictionary}

The Italian reflection dictionary (IREF) is a test analysis list of content words concerning how people think and communicate their thoughts. The dictionary includes basic logic words and words referring to cognitive or logical functions or the failures of these functions. It is a measure of the abstractionintellectualizing process. IREF measures can be processed by DAAP (Maskit, 2021).

\section{Italian Affect Dictionary}

The Italian affect dictionary (IAFF) is a list that contains 1,786 Italian words concerning how people feel and communicate feelings directly. It includes emotion labels, functions associated with affective arousal, and words indicating an emotional response, either positive or negative. Measures can be processed by DAAP (Maskit, 2021).

\section{Data Analysis}

According to the hypotheses of the present work, in order to test for the different working processes of dreams and reports 
TABLE 1 | Comparison COVID-19 pandemic dreams and waking thoughts writing.

\begin{tabular}{|c|c|c|c|c|c|c|c|}
\hline \multirow[t]{2}{*}{ Linguistic measures $^{a}$} & \multicolumn{2}{|c|}{ Dreams N. Segments 247} & \multicolumn{2}{|c|}{ Waking thoughts N. Segments 75} & \multirow[t]{2}{*}{$\mathbf{T}$} & \multirow[t]{2}{*}{$\mathbf{p}$} & \multirow[t]{2}{*}{ Effect size } \\
\hline & $\mathbf{M}$ & SD & $\mathbf{M}$ & SD & & & \\
\hline IREF & 0.03 & 0.02 & 0.04 & 0.03 & -3.135 & $0.002^{\star}$ & -0.41 \\
\hline IWRAD & 0.52 & 0.012 & 0.49 & 0.021 & 9.008 & $0.000^{\star}$ & 1.06 \\
\hline IWRRL & 0.54 & 0.01 & 0.55 & 0.023 & -2.941 & $0.004^{\star}$ & -0.38 \\
\hline ASI & 0.77 & 0.87 & 0.74 & 1.02 & 0.208 & 0.835 & 0.02 \\
\hline
\end{tabular}

Independent $t$-test, ${ }^{*} p<0.01$.

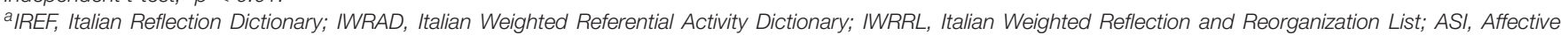
Salience Index.

of waking thoughts in the context of traumatic experiences, a $t$-test comparison has been run involving the IDAAP linguistic measures, ASI, and the individuals' elaborative capacity as independent variables. In order to explore the relationship between ASI and other Linguistic measures in the two types of narratives, Pearson's correlation will be applied in reports of night dreams and waking thoughts.

\section{RESULTS}

The initial results of the two sample groups for the $t$-tests involving age, gender, education, and marital status did not show any significant differences. Further, the Chi-Square analyses didn't show any significant results either. Therefore, we could consider the two sample groups as similar. The $t$-test comparison displayed insightful results; significant differences have been highlighted for several variables. Following our hypothesis, no differences were detected in the ASI comparison between reports of dreams and reports of waking thoughts, as shown in Table 1. We also found a significantly higher level of IWRAD in dreams with a considerable effect size (1.06). Reports of waking thoughts further showed significantly higher levels of IAFF, IREF, and IWRRL.

Additionally, Pearson's correlation also showed some interesting results (see Table 2). While it was found that the ASI is negatively correlated to IWRAD and IWRRL in reports of dreams, there was no correlation in reports of waking thoughts.

\section{DISCUSSION}

Our work explored the different narrative modalities in relation to the same traumatic event caused by the COVID-19 pandemic through the writing of dreams and waking thoughts. Our hypotheses argued that different emotional processes take place in the writing of dreams and in the writing of waking thoughts, therefore expressing a different form of adaptation to the event manifested in reality. Specifically, we hypothesized that the ASI in the narrated texts would not have been different between the narratives of the day and the narratives of the night. ASI, as a measure of arousal activation should be the same, given that the pandemic was shocking for the entire Italian population. Our results confirm our hypothesis. However, although the level of emotional activation was different, we hypothesized that the dream narratives allowed for a greater ability to connect the lived experience to language. In fact, according to the MCT (Severino et al., 1989), dreams are one of the greatest processes of emotional and symbolic connection. Indeed, our results confirm that symbolization processes are significantly greater in dream scriptures. These results further confirm psychodynamic theories (Sands, 2010) which state that dream processes enable the ability to symbolize emotional schemas and to represent negative and anguish feelings. Another hypothesis of ours concerned the processes of reflection/reorganization of the emotional experience. We hypothesized that this process was more involved in the diurnal writings, as an attempt to explain the pandemic situation and find rational solutions to the experience. This hypothesis was also confirmed. During the day, the individual needs to adapt more functionally to reality and disconnect the emotional activation that would otherwise dominate the day as well. During the narratives of the waking thoughts, cognitive organization should prevail.

Our last hypothesis argued that different relationships existed between the arousal shown in the ASI measure and the other linguistic measures referred to the RP.

To verify this hypothesis, we analyzed the correlations between the different measures. We hypothesized that the correlations between the levels of arousal by ASI and the other linguistic measures should be different. Generally, a good level of the RP that allows for the connection between emotions and language implies a correlation between the processes of Symbolization and Reflection/Reorganization. In fact, this process emerges only in dreams, while no correlations

TABLE 2 | Pearson's correlation in reports of dreams and waking thoughts.

\begin{tabular}{lcccc}
\hline & ISAFF & IREF & IWRAD & IWRRL \\
\hline $\begin{array}{l}\text { Dreams } \\
\text { b ASI (n. 247) }\end{array}$ & -0.093 & 0.030 & $-0.136^{*}$ & $-0.218^{* *}$ \\
Waking thoughts & & & & \\
ASI (n.75) & -0.186 & -0.084 & 0.020 & -0.095 \\
\hline
\end{tabular}

Pearson's correlation two tails $p<0.01^{*} ; p<0.001^{* *}$.

a/SAFF, Italian Dictionary of, respectively, Sum of Positive, Negative, Neutral Affects; IREF, Italian Reflection Dictionary; IWRAD, Italian Weighted Referential Activity Dictionary; IWRRL, Italian Weighted Reflection and Reorganization List.

${ }^{b}$ ASI, Affective Salience Index. 
emerge between the measures in waking thoughts, which is also supportive of our hypothesis.

\section{CONCLUSION}

In conclusion, these results open up interesting theoretical speculations regarding the function of dreams. Further research should be carried out to confirm these findings in a more generalized way, concluding that dreams allow for a facilitation in the elaboration of traumatic emotional experiences. Our results support the findings of researchers who found that dreams could play a role in the reorganization of experience, particularly, in reference to memories, trauma, and the general ability of problem solving (Fosshage, 2007; Mariani et al., 2021). These results are in line with the studies on the psychotherapeutic process, which highlight how dream processing allows for the processing of traumatic experiences (Gennaro et al., 2020). Much research has been carried out on dreams in relation to the pandemic and the main findings highlight the central role that emotional processing plays in the dream function. Our results, albeit taken with caution due to the large sample size, show that the nocturnal and diurnal affective processes perform complex but diversified functions, useful for human adaptation and the survival of trauma (Borghi et al., 2021; Giovanardi and Spangler, 2021).

\section{LIMITATIONS}

Despite the interesting results gained evidencing the different emotional processes that took place in the writing of dreams and in the writing of waking thought, limits need not be underestimated. The sample size is quite narrow and limited to a specific population. Nevertheless, this work could be read as preliminary evidence used to implement further studies,

\section{REFERENCES}

Barrett, L. F. (2017). How Emotions are Made: The Secret Life of the Brain. London: Houghton Mifflin Harcourt.

Barrett, L. F., and Lindquist, K. A. (2008). "The embodiment of emotion," in Embodied Grounding: Social, Cognitive, Affective, and Neuroscientific Approaches, eds G. R. Semin and E. R. Smith (Cambridge: Cambridge University Press), 237-262. doi: 10.1017/CBO9780511805837.011

Barrett, L. F., Mesquita, B., Ochsner, K. N., and Gross, J. J. (2007). The experience of emotion. Ann. Rev. Psychol. 58, 373-403. doi: 10.1146/annurev.psych.58. 110405.085709

Beam, C. R., and Kim, A. J. (2020). Psychological sequelae of social isolation and loneliness might be a larger problem in young adults than older adults. Psychol. Trauma 12, 58-60. doi: 10.1037/tra0000774

Beebe, B., and Lachmann, F. M. (2002). Infant Research and Adult Treatment: Co-Constructing Interactions. El Dorado Hills, CA: The Analytic Press.

Berrios, R. (2019). What is complex/emotional about emotional complexity? Front. Psychol. 10:1606. doi: 10.3389/fpsyg.2019.01606

Bion, W. R. (1967). "The imaginary twin," in Second Thoughts, ed. W. Bion (London: Routledge), 3-22. doi: 10.1016/B978-1-4831-9866-8.50004-7

Boag, S. (2020). Reflective awareness, repression, and the cognitive unconscious. Psychoanal. Psychol. 37, 18-27. doi: 10.1037/pap0000276 with similar research designs, to shed light on the specific mechanisms underpinning the workings of dreams. For example, the comparison of the narratives of dreams and waking thoughts in traumatic and non-traumatic contexts could help provide further insight to the mechanisms paving trauma elaboration, which could provide useful implications for clinical practice. A long-term follow-up study could be one relevant direction for future research. Finally, more psychological variables could be researched in further studies in order to explore how they would influence the emotional regulation of individuals.

\section{DATA AVAILABILITY STATEMENT}

The raw data supporting the conclusions of this article will be made available by the authors, without undue reservation.

\section{ETHICS STATEMENT}

The studies involving human participants were reviewed and approved by Ethical Committee of Department of Dynamic and Clinical Psychology, and Health Studies. The patients/participants provided their written informed consent to participate in this study.

\section{AUTHOR CONTRIBUTIONS}

RM contributed to all the phases of the study. AG and SM participated in research design development, in results interpretation, and in writing and editing the manuscript. MD participated in results interpretation and in writing the manuscript. SS supervised and monitored the project. All authors contributed to the article and approved the submitted version.

Bonacini, L., Gallo, G., and Scicchitano, S. (2021). Working from home and income inequality: risks of a 'new normal' with COVID-19. J. Popul. Econ. 34, 303-360. doi: 10.1007/s00148-020-00800-7

Borghi, A. M., and Cimatti, F. (2010). Embodied cognition and beyond: acting and sensing the body. Neuropsychologia 48, 763-773. doi: 10.1016/j. neuropsychologia.2009.10.029

Borghi, L., Bonazza, F., Lamiani, G., Musetti, A., Manari, T., Filosa, M., et al. (2021). Dreaming during lockdown: a quali-quantitative analysis of the Italian population dreams during the first COVID-19 pandemic wave. Res. Psychother. 24, 200-211. doi: 10.4081/ripppo.2021.547

Bornstein, R. F., and Masling, J. M. (1998). Empirical Perspectives on the Psychoanalytic Unconscious. Washington, DC: American Psychological Association. doi: 10.1037/10256-000

Bucci, W. (2021a). Emotional Communication and Therapeutic Change Understanding Psychotherapy Through Multiple Code Theory. London: Routhledge. doi: 10.4324/9781003125143

Bucci, W. (2021b). Overview of the referential process: the operation of language within and between people. J. Psycholinguist. Res. 50, 3-15. doi: 10.1007/s10936021-09759-2

Bucci, W., and Crisafulli, G. (2021). Linguistic measures of the therapeutic process in carl rogers's case of miss vib. J. Psycholinguist. Res. 50, 169-192. doi: 10.1007/ s10936-021-09769-0 
Bucci, W., and Maskit, B. (2007). Beneath the surface of the therapeutic interaction: the psychoanalytic method in modern dress. J. Am. Psychoanal. Assoc. 55, 1355-1397. doi: 10.1177/000306510705500412

Castellini, G., Rossi, E., Cassioli, E., Sanfilippo, G., Innocenti, M., Gironi, V., et al. (2021). A longitudinal observation of general psychopathology before the COVID-19 outbreak and during lockdown in Italy. J. Psychosom. Res. 141:110328. doi: 10.1016/j.jpsychores.2020.11 0328

Creese, J., Byrne, J. P., Conway, E., Barrett, E., Prihodova, L., and Humphries, N. (2021). We all really need to just take a breath": composite narratives of hospital doctors'. well-being during the COVID-19 pandemic. Int. J. Environ. Res. Public Health 18:2051. doi: 10.3390/ijerph18042051

Czeisler, M. É, Howard, M. E., and Rajaratnam, S. M. W. (2021). Mental health during the COVID-19 pandemic: challenges, populations at risk, implications, and opportunities. Am. J. Health Promot. 35, 301-311. doi: 10. $1177 / 0890117120983982 b$

Daly, M., and Robinson, E. (2021). Psychological distress and adaptation to the COVID-19 crisis in the United States. J. Psychiatr. Res. 136, 603-609. doi: 10.1016/j.jpsychires.2020.10.035

Damasio, A. (1999). The Feeling of What Happens: Body and Emotion in the Making of Consciousness. San Diego, CA: Harcourt College Publishers.

Damasio, A. (2010). Self Comes to Mind: Constructing the Conscious Brain. New York, NY: Pantheon.

De Leo, D., and Trabucchi, M. (2020). COVID-19 and the fears of italian senior citizens. Int. J. Environ. Res. Public Health 17:3572. doi: 10.3390/ ijerph17103572

De Roten, Y., Djillali, S., Crettaz von Roten, F., Despland, J. N., and Ambresin, G. (2021). Defense mechanisms and treatment response in depressed inpatients. Front. Psychol. 12:633939. doi: 10.3389/fpsyg.2021.6 33939

Deckert, M., Schmoeger, M., Auff, E., and Willlinger, U. (2020). Subjective emotional arousal: an explorative study on the role of gender, age, intensity, emotion regulation difficulties, depression and anxiety symptoms, and meta-emotion. Psychol. Res. 84, 1857-1876. doi: 10.1007/s00426-01901197-z

Di Trani, M., Mariani, R., Renzi, A., Greenman, P. S., and Solano, L. (2018). Alexithymia according to Bucci's multiple code theory: a preliminary investigation with healthy and hypertensive individuals. Psychol. Psychother. 91, 232-247. doi: 10.1111/papt.12158

Diamandis, E. (2021). The Mother of All Battles: Viruses vs. Humans. Can Humans Avoid Extinction in 50-100 Years? Available online at: https://www.preprints. org/manuscript/202104.0397/v1 (accessed June 10, 2021).

Fornari, F. (1976). Simbolo e Codice: Dal Processo Psicoanalitico Allanalisi Istituzionale. Milano: Feltrinelli.

Fosshage, J. L. (2007). The organizing functions of dreaming: pivotal issues in understanding and working with dreams. Int. Forum Psychoanal. 16, 213-221. doi: 10.1080/08037060701442166

Gallese, V. (2009). "Simulazione incarnata, intersoggettività e linguaggio," in Psicoanalisi e Neuroscienze. Risonanze Interdisciplinari, eds G. Moccia and L. Solano (Milano: Franco Angeli).

Gennaro, A., Kipp, S., Viol, K., de Felice, G., Andreassi, S., Aichhorn, W., et al. (2020). A phase transition of the unconscious: automated text analysis of dreams in psychoanalytic psychotherapy. Front. Psychol. 11:1667. doi: 10.3389/ fpsyg.2020.01667

Gigerenzer, G., and Goldstein, D. G. (1996). Reasoning the fast and frugal way: models of bounded rationality. Psychol. Rev. 103, 650-669. doi: 10.1037/0033295X.103.4.650

Giovanardi, G., and Spangler, P. (2021). Introduction to the special section on working on dreams, from psychotherapy to neuroscience. Res. Psychother. 24, 107-110. doi: 10.4081/ripppo.2021.578

Goleman, D. (1998). Working with Emotional Intelligence. New York, NY: Bantam Books. doi: 10.1002/ltl.40619981008

Green, A. (1977). "Il regno appartiene al bambino," in Il Pensiero di D.W. Winnicott, eds V. Bonamino and A. Giannakoulas (Roma: Armando).

Gross, J. J., and Barrett, L. F. (2011). Emotion generation and emotion regulation: one or two depends on your point of view. Emot. Rev. 3, 8-16. doi: 10.1177/ 1754073910380974
Herbert, C., El Bolock, A., and Abdennadher, S. (2021). How do you feel during the COVID-19 pandemic? A survey using psychological and linguistic selfreport measures, and machine learning to investigate mental health, subjective experience, personality, and behaviour during the COVID-19 pandemic among university students. BMC Psychol. 9:90. doi: 10.1186/s40359-021-00574-x

Iorio, I., Sommantico, M., and Parrello, S. (2020). Dreaming in the time of COVID19: a quali-quantitative Italian study. Dreaming 30, 199-215. doi: 10.1037/ drm0000142

Klein, M. (1937). "Love, guilt and reparation," in Love, Guilt and Reparation and Other Works, ed. M. Klein (New York, NY: The Free Press), 306-343.

Kramer, U., Beuchat, H., Grandjean, L., and Pascual-Leone, A. (2020). How personality disorders change in psychotherapy: a concise review of process. Curr. Psychiatry Rep. 22:41. doi: 10.1007/s11920-020-01162-3

Lang, P. J., Bradley, M. M., and Cuthbert, B. N. (1999). International Affective Picture System (IAPS): Technical Manual and Affective Ratings. Gainesville, FL: Center for Research in Psychophysiology.

Li, S., Wang, Y., Xue, J., Zhao, N., and Zhu, T. (2020). The impact of COVID-19 epidemic declaration on psychological consequences: a study on active weibo users. Int. J. Environ. Res. Public Health 17:2032. doi: 10.3390/ijerph17062032

MacKay, C., and DeCicco, T. L. (2020). Pandemic dreaming: the effect of COVID19 on dream imagery, a pilot study. Dreaming 30, 222-234. doi: 10.1037/ drm0000148

Mariani, R., Di Trani, M., Negri, A., and Tambelli, R. (2020). Linguistic analysis of autobiographical narratives in unipolar and bipolar mood disorders in light of multiple code theory. J. Affect. Disord. 273, 24-31. doi: 10.1016/j.jad.2020.03. 170

Mariani, R., and Hoffman, L. (2021). Analytic process and linguistic style: exploring analysts' treatment notes in the light of linguistic measures of the referential process. J. Psycholinguist. Res. 50, 193-206. doi: 10.1007/s10936-021-09771-6

Mariani, R., Maskit, B., Bucci, W., and De Coro, A. (2013). Linguistic measures of the referential process in psychodynamic treatment: the English and Italian versions. Psychother. Res. 23, 430-447. doi: 10.1080/10503307.2013.794399

Mariani, R., Monaco, S., Christian, C., and Di Trani, M. (2021). Dreaming in quarantine: linguistic analysis of referential process of dreams during COVID19 pandemic lockdown. Res. Pychother. 24:537. doi: 10.4081/ripppo.2021.537

Maskit, B. (2021). Overview of computer measures of the referential process. Psycholinguist. Res. 50, 29-49. doi: 10.1007/s10936-021-09761-8

Matte Blanco, I. (1981). Linconscio Come Insiemi Infiniti. Torino: Einaudi.

McClelland, J. L., Rumelhart, D. E., and Hinton, G. E. (1989). "The appeal of parallel distributed processing," in Parallel Distributed Processing: Explorations in the Microstructure of Cognition, eds D. E. Rumelhart and J. L. McClelland (Cambridge: MIT Press), 3-44.

McGaugh, J. L. (2004). The amygdala modulates the consolidation of memories of emotionally arousing experiences. Ann. Rev. Neurosci. 27, 1-28. doi: 10.1146/ annurev.neuro.27.070203.144157

Mota, N. B., Weissheimer, J., Ribeiro, M., de Paiva, M., Avilla-Souza, J., Simabucuru, G., et al. (2020). Dreaming during the Covid-19 pandemic: computational assessment of dream reports reveals mental suffering related to fear of contagion. PLoS One 15:e0242903. doi: 10.1371/journal.pone.0242903

Muramatsu, R., and Hanoch, Y. (2005). Emotions as a mechanism for boundedly rational agents: the fast and frugal way. J. Econ. Psychol. 26, 201-221. doi: 10.1016/j.joep.2004.03.001

Murray, E. J., and Segal, D. L. (1994). Emotional processing in vocal and written expression of feelings about traumatic experiences. J. Trauma Stress 7, 391-405. doi: $10.1007 / \mathrm{BF} 02102784$

Museum of London. (2020). Museum of Dreams Project (Creator Sliwinski, S.). Available online at: https://www.museumoflondon.org.uk/news-room/pressreleases/museum-london-collect-covid-dreams (accessed June 10, 2021).

Negri, A., Andreoli, G., Barazzetti, A., Zamin, C., and Christian, C. (2020). Linguistic markers of the emotion elaboration surrounding the confinement period in the italian epicenter of COVID-19 outbreak. Front. Psychol. 18:568281. doi: 10.3389/fpsyg.2020.568281

Negri, A., Christian, C., Mariani, R., Belotti, L., Andreoli, G., and Danskin, K. (2019). Linguistic features of the therapeutic alliance in the first session: a psychotherapy process study. Res. Psychother. 22, 71-82. doi: 10.4081/ripppo. 2019.374

Negri, A., Esposito, G., Mariani, R., Savarese, M., Belotti, L., Squitieri, B., et al. (2018). "The Italian weighted reflection and reorganization list (I-WRRL): a 
new linguistic measure detecting the third phase of the referential process," in Paper Presented at: XII Congresso Nazionale della Società per la Ricerca in Psicoterapia SPR-Italia, Palermo.

Negri, A., and Ongis, M. (2021). Stimulus features of the object relations technique affecting the linguistic qualities of individuals' narratives. J. Psycholinguist. Res. 50, 65-83. doi: 10.1007/s10936-021-09764-5

Panksepp, J. (1998). Affective Neuroscience: The Foundations of Human and Animal Emotions. Oxford: Oxford University Press.

Panksepp, J. (2005). Affective consciousness: core emotional feelings in animals and humans. Conscious. Cogn. 14, 30-80. doi: 10.1016/j.concog.2004.10.004

Pennebaker, J. W. (2000). Telling stories: the health benefits of narrative. Lit. Med. 19, 3-18. doi: 10.1353/lm.2000.0011

Pesonen, A. K., Lipsanen, J., Halonen, R., Elovainio, M., Sandman, N., Makela, J. M., et al. (2020). Pandemic dreams: network analysis of dream content during the COVID-19 lockdown. Front. Psychol. 11:2569. doi: 10.3389/fpsyg. 2020.573961

Polkinghorne, D. E. (1995). Narrative configuration in qualitative analysis. Int. J. Qual. Stud. Educ. 8, 5-23. doi: 10.1080/0951839950080103

Posner, J., Russell, J. A., and Peterson, B. S. (2005). The circumplex model of affect: an integrative approach to affective neuroscience, cognitive development, and psychopathology. Dev. Psychopathol. 17, 715-734. doi: 10. 1017/S0954579405050340

Rab, S., Javaid, M., Haleem, A., and Vaishya, R. (2020). Face masks are new normal after COVID-19 pandemic. Diabetes Metab. Syndr. 14, 1617-1619. doi: 10.1016/ j.dsx.2020.08.021

Rachman, S. (2001). Emotional processing, with special reference to posttraumatic stress disorder. Int. Rev. Psychiatry 13, 164-171. doi: 10.1080/ 09540260120074028

Renzi, A., Mariani, R., Di Trani, M., and Tambelli, R. (2020). Giving words to emotions: the use of linguistic analysis to explore the role of alexithymia in an expressive writing intervention. Res. Psychother. 7:452. doi: 10.4081/ripppo. 2020.452

Rossi, R., Socci, V., Talevi, D., Mensi, S., Niolu, C., Pacitti, F., et al. (2020). COVID19 pandemic and lockdown measures impact on mental health among the general population in Italy. Front. Psychiatry 11:790. doi: 10.3389/fpsyt.2020. 00790

Russell, J. A., and Barrett, L. F. (1999). Core affect, prototypical emotional episodes, and other things called emotion: dissecting the elephant. J. Pers. Soc. Psychol. 76, 805-819. doi: 10.1037/0022-3514.76.5.805

Salvatore, S., and Freda, M. F. (2011). Affect, unconscious and sensemaking. A psychodynamic, semiotic and dialogic model. New Ideas Psychol. 29, 119-135. doi: 10.1016/j.newideapsych.2010.06.001

Salvatore, S., Gelo, O., Gennaro, A., Metrangolo, R., Terrone, G., Pace, V., et al. (2017). An automated method of content analysis for psychotherapy research: a further validation. Psychother. Res. 27, 38-50. doi: 10.1080/10503307.2015. 1072282

Salvatore, S., Gennaro, A., Auletta, A. F., Tonti, M., and Nitti, M. (2012). Automated method of content analysis: a device for psychotherapy proc ess research. Psychother. Res. 22, 256-273. doi: 10.1080/10503307.2011.647930

Sands, S. H. (2010). On the royal road together: the analytic function of dreams in activating dissociative unconscious communication. Psychoanal. Dialogues 20, 357-373. doi: 10.1080/10481885.2010.502469

Scherer, K. R. (2005). What are emotions? and how can they be measured? Soc. Sci. Inf. 44, 695-729. doi: 10.1177/0539018405058216

Severino, S. K., Bucci, W., and Creelman, M. L. (1989). Cyclical changes in emotional information processing in sleep and dreams. J. Am. Acad. Psychoanal. 17, 555-577. doi: 10.1521/jaap.1.1989.17.4.555

Solano, L. (2013). "Lo psicologo ovunque possibile," in Tra Mente e Corpo, ed. L. Solano (Milano: Raffaello Cortina Editore), 485-516.

Storbeck, J., and Clore, G. L. (2008). The affective regulation of cognitive priming. Emotion 8, 208-215. doi: 10.1037/1528-3542.8.2.208

Valsiner, J. (2021). General Human Psychology: Theory and History in the Human and Social Sciences. Basel: Springer International Publishing.

Viscuso, D. G. I., and Mangiapane, D. E. (2020). Pandemic Covid-19: psychodynamic analysis of a global trauma. Clinical considerations pre/post Lock down. J. Med. Res. Health Sci. 3, 976-990. doi: 10.15520/jmrhs.v3i6.194

Wang, Y., Shi, L., Que, J., Quingdong, L., Lin, L., Zhengan, L., et al. (2021). The impact of quarantine on mental health status among general population in China during the COVID-19 pandemic. Mol. Psychiatry 1-10. doi: 10.1038/ s41380-021-01019-y

Conflict of Interest: The authors declare that the research was conducted in the absence of any commercial or financial relationships that could be construed as a potential conflict of interest.

Publisher's Note: All claims expressed in this article are solely those of the authors and do not necessarily represent those of their affiliated organizations, or those of the publisher, the editors and the reviewers. Any product that may be evaluated in this article, or claim that may be made by its manufacturer, is not guaranteed or endorsed by the publisher.

Copyright (C) 2021 Mariani, Gennaro, Monaco, Di Trani and Salvatore. This is an open-access article distributed under the terms of the Creative Commons Attribution License (CC BY). The use, distribution or reproduction in other forums is permitted, provided the original author(s) and the copyright owner(s) are credited and that the original publication in this journal is cited, in accordance with accepted academic practice. No use, distribution or reproduction is permitted which does not comply with these terms. 